\title{
Structural Basis of Joint Instability as Cause for Chronic Musculoskeletal Pain and Its Successful Treatment with Regenerative Injection Therapy (Prolotherapy)
}

\author{
R.A. Hauser ${ }^{1, *}$, P.J. Blakemore ${ }^{2}$, J. Wang ${ }^{3}$ and D. Steilen ${ }^{1}$ \\ ${ }^{1}$ Caring Medical Rehabilitation Services, Oak Park, IL, USA; ${ }^{2}$ Michigan State University College of Orthopedic \\ Medicine, East Lansing, MI, USA; ${ }^{3}$ Department of Orthopedic Surgery, Kansas Medical Center, Kansas City, KS, USA
}

\begin{abstract}
Joint dysfunctions and associated musculoskeletal pain are among the most common medical complaints presented to clinicians. Ligaments are collagenous fibrous structures that are primarily responsible for maintaining smooth joint motion, restraining excessive joint displacement, and providing stability across the joint. Ligaments also act as sensory organs for the joints and have significant input to pain sensation. When ligaments are subjected to forces beyond their normal range of motion, injury and failure occur, resulting in joint laxity (looseness or instability), and subsequent disruptions in the balance between joint mobility and joint stability. These dysfunctions can result in joint pain and the development of osteoarthritis. Several strategies have been employed over the years in attempts to improve joint instability from ligament injury; however, some of the standard therapeutic approaches (drugs, corticosteroid injections, and surgery) employed to address these problems have not been very effective because they often do not address the underlying cause of the problems, and in fact can inhibit ligament healing and restoration. For these reasons, there is current and growing interest among patients and clinicians in prolotherapy, an alternative therapeutic modality that can reduce or eliminate pain by stimulating the natural regenerative processes in and around the joint to facilitate the restoration of degenerated ligaments and tendons to a healthy state, improving joint support, function and reducing pain. This review presents current evidence from clinical studies demonstrating that prolotherapy is a significant and effective alternative treatment modality for people with ligament-related injuries and resultant joint instability.
\end{abstract}

Keywords: Chronic musculoskeletal pain, drugs, joint instability, ligament, ligament healing, ligament injury, ligamentous laxity, osteoarthritis, prolotherapy, regenerative injection therapy, regenerative medicine, surgery.

\section{INTRODUCTION}

There is a strong and growing support for the idea that chronic pain is a distinct condition that coexists with other health conditions, and as such must be assessed and managed $[1,2]$. The most frequently reported chronic pain conditions are associated with musculoskeletal dysfunction and degeneration. New data from a recent study, Global Burden of Disease 2010, highlight that increasing pain and disability associated with musculoskeletal disorders affect more than 1.7 billion people worldwide and have the $4^{\text {th }}$ greatest impact on the overall health of the world population, considering both death and disability. This burden has increased by $45 \%$ during the past 20 years and is predicted to continue to escalate due to aging, increased obesity, and lack of physical activity $[3,4]$.

In the United States, musculoskeletal disorders and diseases are the leading cause of disability, which account for more than half of all chronic pain conditions in people over 50 years of age. Census data collected in 2008 indicates that musculoskeletal conditions are among the highest prevalence of self-reported primary medical conditions reported by persons aged 18 and older [3, 4]. It is estimated

\footnotetext{
*Address correspondence to this author at the Caring Medical Rehabilitation Services, Oak Park, IL, USA; Tel: (708) 848-7789; Fax: (708) 848-7763; E-mail: drhauser@caringmedical.com
}

that musculoskeletal joint conditions, in particular, affect between 100 million and 116 million people in the United States, and more than 1 in 4 persons require medical attention due to associated pain and disability. The impact of chronic musculoskeletal joint pain on individuals, families, and society is monumental; the morbidity costs of these disorders restrict activities of daily living, cause lost work days, and are a major cause of life long pain. Annual direct and indirect costs for joint and bone health are approximately $\$ 849$ billion - $7.7 \%$ of the gross domestic product. It is estimated that the burden of musculoskeletal conditions is expected to substantially increase in the next 10 to 20 years due to the aging population and sedentary lifestyles [4-6].

\section{PATHOPHYSIOLOGY OF JOINT PAIN}

Any damage to the joints from disease or injury can interfere with movement or range of motion and cause severe pain. The International Association for the Study of Pain defines pain as ". . . an unpleasant sensory and emotional experience that is associated with actual or potential tissue damage or described in such terms" [7]. Joint pain can be acute or chronic and may have multiple causes, including joint injury, crystal deposition, infection, and disease arising from inflammation.

Most often, joint pain occurs when sensory receptors called nociceptors detect signals from damaged tissue, 
including ligaments. Nociceptors are free (bare) nerve endings that mainly originate in the dorsal root and trigeminal ganglia. They are associated with one of the two types of persistent pain (the other is neuropathic pain, occurs when nerves in the central or peripheral nervous system are damaged). When stimulated, nociceptors release a large number of neuromediators, such as substance $\mathrm{P}$ and the calcitonin gene-related peptide. Complex neuronal activation occurs, which involves not only local sensitization but also modifications in central pain pathways [8].

Joint pain may arise from structures within or adjacent to the joint. As an example, enthesopathy is a painful disorder at the site of the insertion of ligaments, tendons, fascia, or articular capsule into bone (enthesis) and is the result of an inflammatory rheumatic or non-rheumatic disease process. In enthesopathy, pain develops in the free nerve endings of entheses (enthesalgia), becoming a source of chronic musculoskeletal pain in some individuals. This process also may promote abnormal calcification or ossification of the tendon or ligament at the insertion into the bone.

\section{Prolotherapy}

Prolotherapy is recognized as one of the most effective complementary and alternative medical (CAM) therapies to treat chronic musculoskeletal pain. This therapeutic approach, used in clinical practice for more than 100 years, was formalized by Hackett in the 1950 s as a viable therapeutic strategy to treat ligamentous laxity and related musculoskeletal conditions $[9,10]$. Prolotherapy entails the injection of any substance that promotes growth of normal or injured cells or tissues; it is a non-pharmacotherapeutic and non-surgical alternative that involves injecting small volumes of an irritant solution into painful ligaments and tendon insertions (enthuses, ligament or tendon attachment site to bone at the fibro-osseous junction), joints, and in adjacent joint spaces over several treatment sessions [1114]. Much of the pain associated with musculoskeletal injuries resulting in laxity and weakness is enthesopathy pain that occurs at the fibro-osseous junction, where ligaments and tendons attach to bone. Prolotherapy injections are done onto the periosteum (except for intraarticular injections) to stimulate the ligaments and tendons to proliferate in the injection area by naturally promoting tissue rejuvenation through the normal inflammatory healing cascade. A major goal of prolotherapy treatment of chronic musculoskeletal conditions is the stimulation of the natural regenerative processes in the joint that will facilitate the restoration of degenerated ligaments and tendons to a healthy state, and thus, improve joint stability, support, function and reduce pain for patient. Prolotherapy is also referred to as proliferation therapy or regenerative injection therapy (RIT). The technique of prolotherapy is founded on the myofascial hypothesis, in which painful muscle spasms are secondary and appear as late sequelae of ligamentous laxity and joint hypermobility or instability. Thus, treatment of the ligament injury-induced myofascial pain should be targeted to restore the ligament and tendon structure. Complete stabilization of the joint and ligament and tendon tissue can then naturally resolve the ligament injuryinduced muscle spasms and the trigger points [14-19].

\section{Joints and Ligaments - Anatomy, Function and Biochemical Constituents}

Determination of the anatomic part responsible for joint pain is often a difficult task, but it is critical, in that it guides appropriate approach to diagnosis and therapy. Thus, knowledge of the anatomy of complex synovial joints (e.g., the knee, shoulder, and ankle), causes and typical mechanisms of injury/pain and presenting signs/symptoms are an important prerequisite for effective treatment.

Joints link the bones of the skeletal system into a functional whole - a system that supports the body, permits effective movement, and protects the softer organs. Joints such as the knee, elbow, and shoulder are self-lubricating, almost frictionless, and able to bear heavy loads and withstand compression while executing smooth and precise movements when healthy [20]. However, it is equally important that other joints be less movable or even immobile in order to protect delicate organs. For example, the vertebral column is only moderately movable, which allows for flexibility of the torso and yet protect the delicate spinal cord and support much of the body's weight.

Joints are generally classified into nonsynovial and synovial joints. Nonsynovial joints lack a synovial lining bordering the joint cavity and do not allow for low-friction or large-range movements. Different kinds of nonsynovial joints are found throughout the body, including symphyses, syndesmoses, and synchondroses. Because the most familiar type of joint is the synovial, this review will focus primarily on discussing joint instability and resultant pain arising from synovial joint disorders. Synovial joints are the most structurally complex type of joint and are the most likely to develop uncomfortable and crippling dysfunctions. Examples of synovial joints are knee, hip, shoulder, elbow, ankle, wrist and jaw. There are six basic classes of synovial joints: ball-and-socket, condylar (ellipsoid), saddle, plane (gliding), hinge and pivot joints. Accessory structures associated with a synovial joint include ligaments, tendons, muscles, bursae, labrum (in the shoulder and hip), and menisci (in the knee joint only) [20].

Ligaments play an important role in the function of synovial joints. Ligaments are specialized dense bands of tough, fibrous collagenous connective tissue bundles that attach one bone to another. Ligaments function to hold bones in approximation, assist joint proprioception and provide mechanical support and stability. Ligaments enable smooth joint motion under normal, physiologic circumstances and prevent excessive joint displacement under high loads [20]. Ligaments vary in size, shape, orientation and location [21]. Under polarized light, ligament microstructure shows collagen bundles align along the long axis of the ligament and display an underlying crimp along the length. This crimp may be involved with the biomechanics associated with the ligament's loading state. Increased loading is thought to cause segments of the ligament to uncrimp, allowing the ligament to elongate without withstanding damage [21]. At the microscopic level, ligaments are composed of fibroblasts that are interspersed in the parallel bundles of collagen matrix and responsible for matrix synthesis. Biochemically, two-thirds of a ligament's total weight is composed of water, which contributes to the cellular function and viscoelastic properties. The remaining one-third of the components of 
ligaments include proteoglycans, elastin, proteins, glycoproteins and collagen. Type I collagen is the major solid constituent $(70-80 \%$ dry weight) and is primarily responsible for tensile strength; Types III, VI, V, XI collagen are also present in lesser amounts (8-12\% dry weight) [21, 22].

The complex interactions of collagen with elastin, proteoglycans, ground substance, and water results in the time- and history-dependent viscoelastic behaviors of ligaments, helping to provide joint homeostasis. In response to various tensile loading protocols, ligaments exhibit hysteresis (i.e. internal energy dissipation), creep, and stress relaxation. In other words, ligaments load relax which means that loads/stresses decrease within the ligament if they are pulled to constant deformations; ligaments also creep which is defined as the deformation (or elongation) under a constant or cyclically repetitive load. Creep is particularly important when considering joint injury as excessive creep could result in laxity of the joint thus predisposing it to further injury (Fig. 1). Another function of ligaments is their role in joint proprioception, which is referred to as the conscious perception of limb position in space. When ligaments are strained, they invoke neurological feedback signals that then activate muscular contraction and this appears to play a role in joint stability and position sense [21, 22].
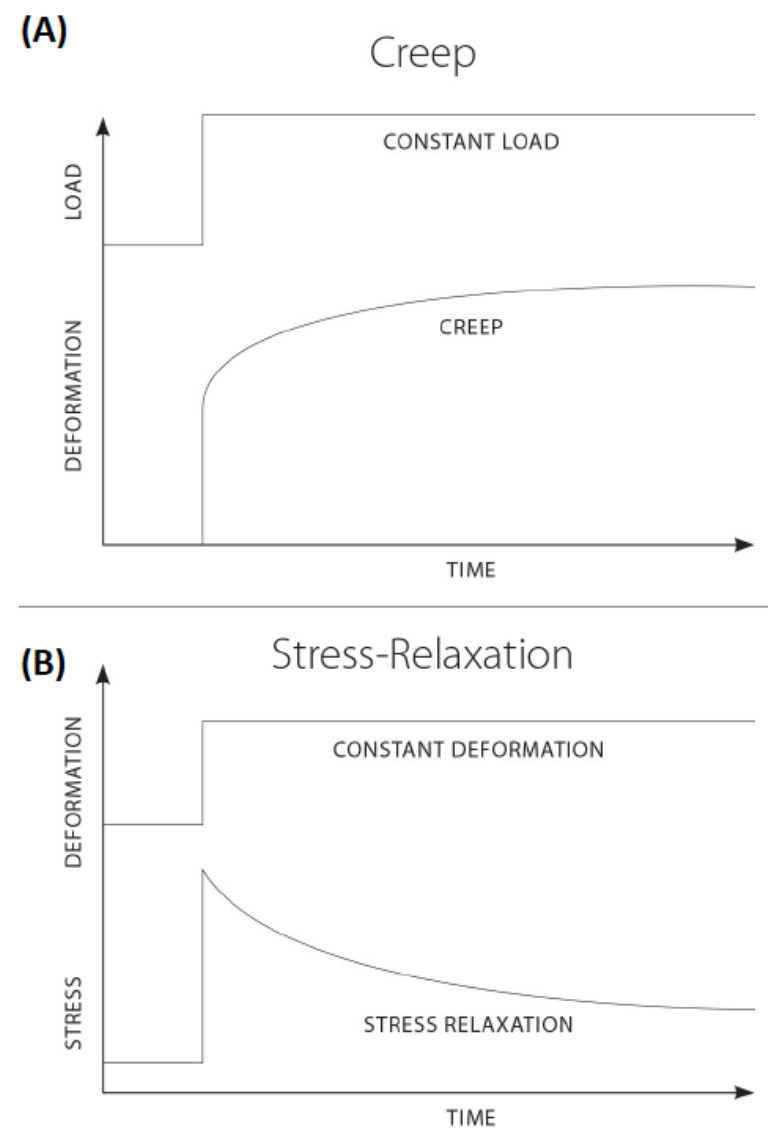

Fig. (1). Creep and stress relaxation. (a) When subjected to a constant stress, ligaments display creep behavior: a time-dependent increase in strain. (b) When ligaments are subjected to a long constant strain, they exhibit a decrease in the stresses within the material known as stress-relaxation.
Ligaments are inserted to bone in two ways: indirect fibrous insertion and direct fibrocartilaginous insertion. Ligaments are most often connected to bone indirectly through fibrous insertion. Superficial fibers insert into the periosteum and deep fibers insert directly into bony lamellae via perforating collagen fibers. At insertion, endotenon becomes continuous with periosteum. Through direct fibrocartilaginous insertion, fibers insert directly into the periosteum surrounding the bone [22, 23] (Fig. 2). Transition of ligament to bone occurs in four zones:

Zone 1 - Ligament proper: Consists of well-aligned type I collagen fibers with small amounts of proteoglycan decorin.

Zone 2 - Fibrocartilage: Consists of types II and III collagen, with small amounts of type I, IX and X collagen, and proteoglycans (aggrecan and decorin).

Zone 3 - Mineralized fibrocartilage: consists of type II collagen, with significant amounts of type $\mathrm{X}$ collagen and aggrecan.

Zone 4 - Bone: Consists of type I collagen, with high mineral content $[22,23]$.

\section{Ligament Injury, Joint Laxity and Instability}

Ligaments function primarily to maintain smooth joint motion, restrain excessive joint displacement, and provide stability across the joint. For example, ligaments of the knee provide passive stability, guide the motion of the femur and tibia, define contact mechanics between the femur and tibia, and restrain excessive motion to prevent dislocation [24]. When the forces to which ligaments are subjected are too great, failure occurs, resulting in drastic changes in the structure and physiology of the joint. Ligamentous injuries can result in joint laxity, which presents as looseness or instability of the joint; this can occur at almost every joint in the body, particularly synovial joints, which are highly dependent on the ligaments for stability.

Ligaments are the primary passive joint stabilizers whereas muscles are the active joint stabilizers. Mechanical laxity refers to an excess in the range of motion in the joint due to loss of integrity of the ligaments and other soft tissues which contribute to joint stability. Functional instability refers to a sense of instability or giving out of the joint experienced in the course of daily activities or strenuous exercise. It is possible to have functional joint instability from muscle weakness alone; thus functional instability may or may not be associated with mechanical laxity [25].

Ligament injuries create disruptions in the balance between joint mobility and joint stability, causing abnormal force transmission through the joint, which results in damage to other structures in and around the joint, including the articular cartilage. Ligament injuries are among the most common causes of musculoskeletal joint laxity, and the resultant pain and disability encountered in primary care practice today. Medial collateral ligaments (MCL) and anterior cruciate ligaments (ACL) are the most frequently injured tissues within the knee joint. For example, about 150,000 ACL injuries occur annually in the United States, and more than 4 million knee arthroscopies are performed worldwide each year. ACL tears rank second to ankle sprains (torn ligaments and tendons) as the leading cause of injury in 

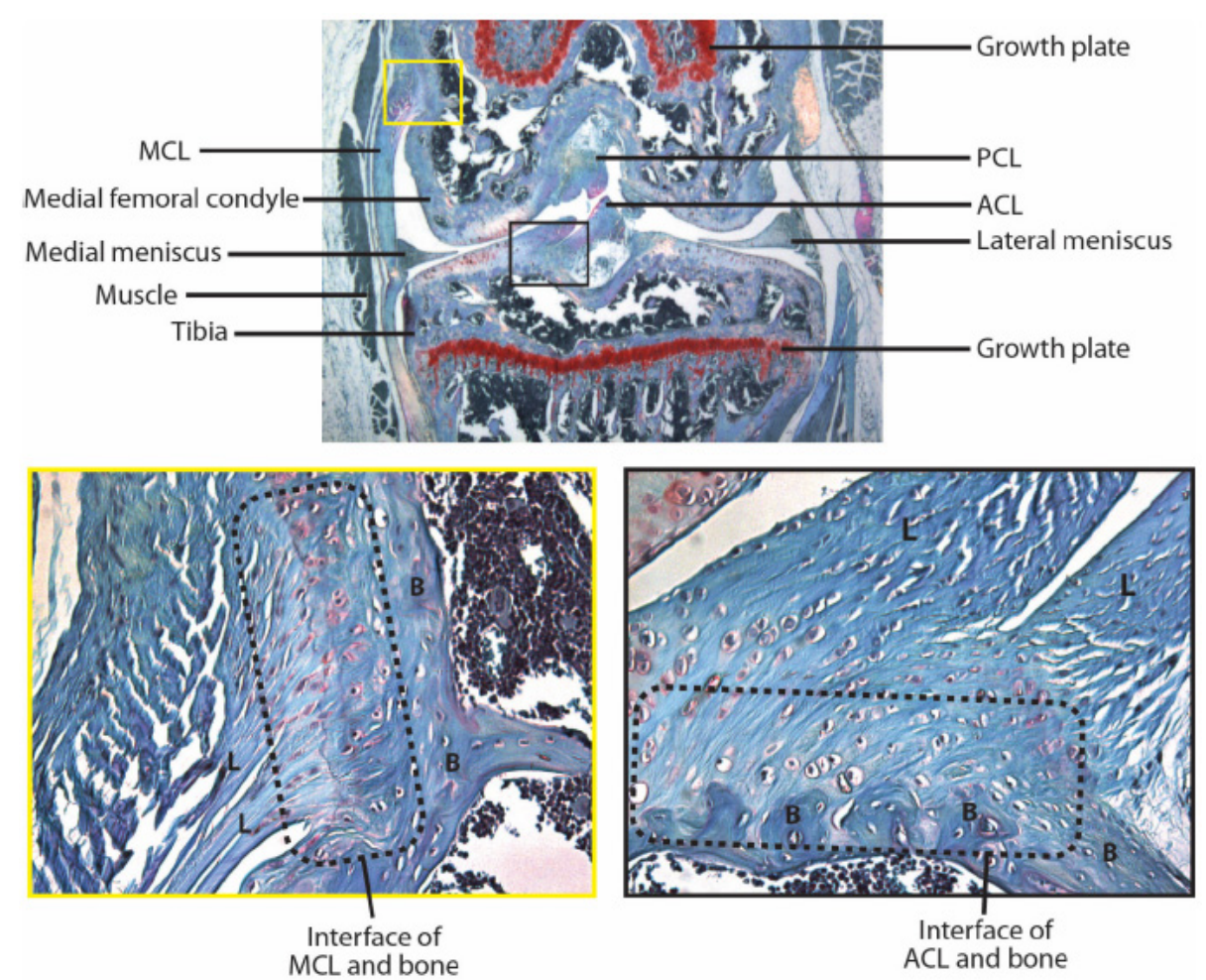

Fig. (2). Microstructures of ligament-bone interfaces. Upper panel: A photomicrograph $(25 \mathrm{x})$ of a mouse knee joint at the age of 8 months shows intraarticular and peri-articular ligaments as well as other joint tissues. MCL = medial collateral ligament (tibial collateral ligament), PCL = posterior cruciate ligament, ACL = anterior cruciate ligament. Note, PCL and ACL are not intact at this sectioning plane; cartilage cells and their matrices are stained in red by Safranin-O; normal growth plate is still observable at this age in rodents. Lower left panel: A photomicrograph (200x) from the area outlined with a yellow box in the upper panel shows the MCL-bone interface (dotted rectangular box). Lower right panel: A photomicrograph (200x) from the area outlined with a black box in the upper panel shows the ACLbone interface (dotted rectangular box). Both lower panels demonstrate interdigitation of ligament and bone tissues in the interface areas. Cartilage cells (stained in red) within fibrocartilage is observed in and adjacent to the interface areas. $\mathrm{L}=$ ligament, $\mathrm{B}=$ bone. Safranin-O and fast green staining.

college athletes, and are reported to be the leading cause of knee injuries in children. Damage to the ACL causes the highest incidence of pathologic joint instability [26, 27]. ACL ruptures, in some cases, are associated with marked short term morbidity and long-term consequences, such as degeneration of the joint surfaces, development of osteoarthritis, moderate to severe disabilities, joint instability and chronic pain $[24,28,29]$. ACL damage typically occurs in the younger population and, as such, leads to prolonged disability and economic cost largely due to work loss [30].

\section{Ligament Response to Injury and Healing Process}

When ligaments are injured, a healing response is initiated in an attempt to repair the damage. The degree of healing and repair is dependent on the ligament's location and the amount of damage that has occurred. Ligaments with greater vascularity (i.e., MCL) have the ability to undergo substantial repair, whereas other ligaments (i.e., ACL) are more limited in their ability to heal, and restore joint strength and stability. Once an ACL is injured, natural healing can, at best, restore it to $50-70 \%$ of its pre-injury tensile strength [31]. As a full recovery to its pre-injury abilities does not occur, the joint is subjected to instability. This inevitably leads to biomechanical changes across joint surfaces, increasing the risk for degenerative changes and the development of osteoarthritis [24, 28, 32, 33]. In few cases, through a three-stage overlapping healing process (hemorrhage with inflammation, cellular and matrix proliferation and finally, remodeling and maturation), the body may be able to repair the injury enough for a full clinical recovery of the initial structural/functional abilities (i.e., strength and ability to stabilize the joint), but this healing process can take months to resolve itself and underlying instability may still be present. If the injury is severe or if multiple injuries have taken place at a joint, the damage to the surrounding ligamentous, tendinous and cartilaginous tissues and other structures of the joint can reach a state that is beyond the body's ability to fully repair and restore.

While there is a vast body of knowledge available regarding the structure and function of normal ligaments, there is less literature addressing the effects of injury on ligament structure and function in terms of the variability and unpredictable nature of ligament healing. Ligament injuries result in significant physiological and structural changes and lead to complex and dynamic cellular processes during healing. Depending on the functional demands placed on the ligament in question, these healing processes cause profound alterations in the biology and biomechanics of the injured ligament, resulting in inadequate healing and tissue formation that is inferior (morphologically, biochemically and biomechanically) to the original tissue (Table 1) [34]. 
Table 1. Biochemical differences between normal and scarred ligaments.

\begin{tabular}{|c|c|}
\hline Normal Ligaments & Ligament Scars \\
\hline \hline Biomodal (large) collagen fibrils & Smaller collagen fibrils \\
\hline Cell and matrix turnover low & Cell and matric turnover high \\
\hline Collagen aligned & Collagen disorganized \\
\hline Collagen densely packed & Flaws between fibers \\
\hline High matrix-cell ratio & Lower matrix cell-ratio \\
\hline Low cell density & Higher cell density \\
\hline Mature collagen cross-links & Immature collagen crosss-links \\
\hline Primary collagen type 1 & More collagen type 3 \\
\hline Primaly small proteoglycans & Larger proteoglycans \\
\hline Rare cell division & More cell division \\
\hline
\end{tabular}

\section{Biomechanical Consequences of Ligament Injury on Joint Instability and Chronic Pain}

Incomplete healing and lower functional integrity of the new ligament tissue may result in ligament laxity, joint instability, and secondary muscle weakness, which predispose the joint to osteoarthritis (OA). Studies on athletes who were followed for 5 to 12 years after a ligament injury have revealed an early onset of OA of the joint and an inability to return to their pre-injury level of activity [28, $35-38$ ]. At 10 years $21 \%-48 \%$ of these athletes were found to have OA. A separate study on female athletes for 12 years after an ACL injury reported that $50 \%$ of the females had radiographic OA and approximately $80 \%$ had other features of OA [39]. Thus, sports trauma, which begins with ligament injury and subsequent laxity, can cause joint instability, which then leads to chronic pain, diminished function, and ultimately to OA of the affected joint $[28,35,38]$. Despite the use of numerous strategies over the years, attempts to improve ligament healing after injury have not been entirely successful. OA remains one of the long-term consequences of ligament injury and continues to be the most common joint disorder of the world [28, 40, 41]. Therefore, understanding the complex cellular processes that occur after ligament injury, as well as determining and implementing those strategies that optimize ligament restoration, are necessary steps in reducing the enormous individual and public health burden of ligament injury-associated $\mathrm{OA}$ and its related chronic musculoskeletal pain.

\section{Ligament Laxity - Pathway to Chronic Joint Pain and Osteoarthritis}

$\mathrm{OA}$ is one of the most common consequences of ligament damage, and subsequent laxity. Traditionally, the pathophysiology of OA was thought to be due to aging and wear and tear on a joint, but more recent studies have shown that ligament injury is one of the initial causes for the development of OA $[28,42,43]$. The possible mechanisms of ligament injury-associated development of OA and proposed prolotherapy healing are illustrated in (Fig. 3). [24, 28, 35].

It is evident from published scientific and medical literature that enormous efforts and resources have been devoted over the years to characterizing and discussing

\section{Pathophysiology of Osteoarthritis}

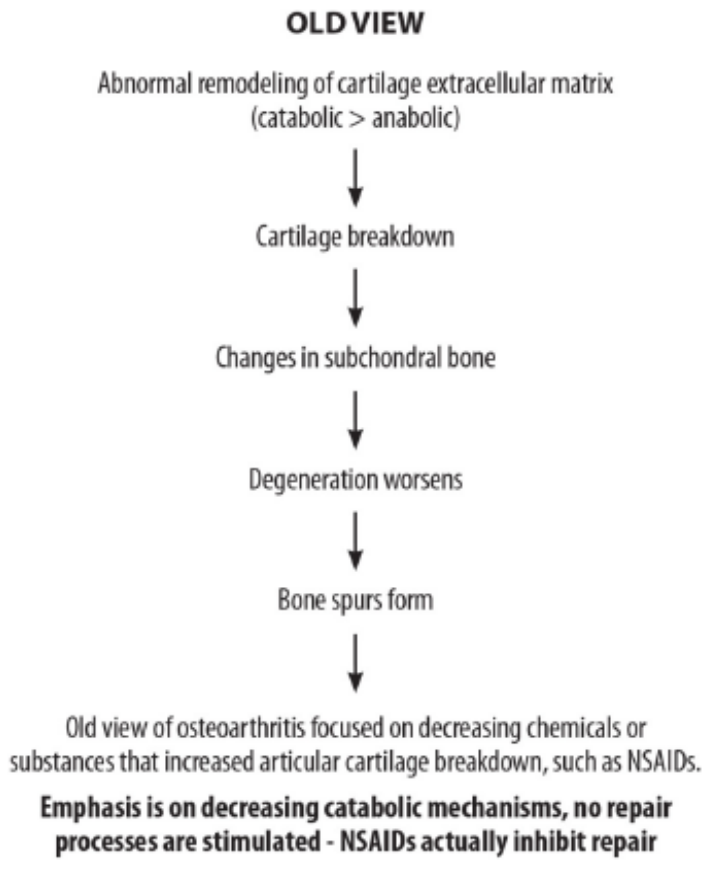

OLDVIEW

vs.

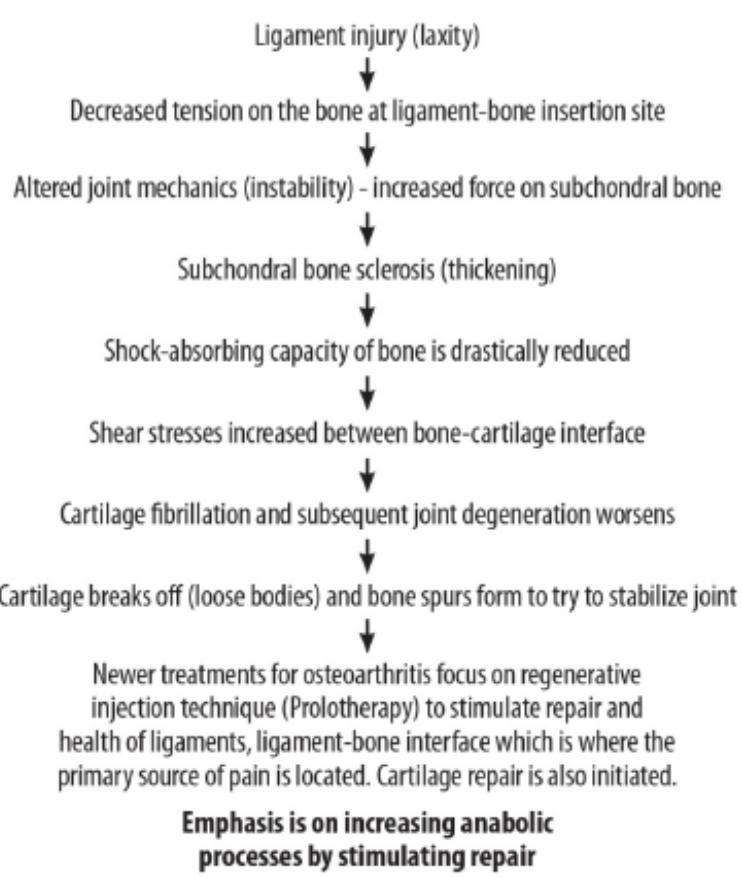

Fig. (3). A new view on osteoarthritis. 
osteoarthritic articular cartilage degeneration or loss. Consequently, the structural or anatomical basis for disease and its molecular pathogenesis has been viewed mostly in terms of cartilage [44, 45]. Although it is not disputed that changes in articular cartilage play a crucial role in the pathophysiology of OA, it has been suggested that considering $\mathrm{OA}$ as primarily a disease of articular cartilage is too simplistic [46]. Indeed, emerging evidence from the application of magnetic resonance imaging (MRI) in early OA has confirmed several different anatomical or structural abnormalities within diseased joints [47-50]. Furthermore, the earliest structural changes seen in some models of spontaneous $\mathrm{OA}$ in the knee joint occur first in the cruciate ligaments, while the subchondral bone and articular cartilage are secondarily affected. The subchondral bone sclerosis, often being the first radiographic evidence of OA, is thought to occur because of increased pressure on the joint secondary to poor joint mechanics $[35,45,51,52]$. Thus, key emerging research findings demonstrate that several types of primary OA show ligament-related pathology at the time of clinical presentation [52]. Although there is also emerging evidence for OA initiation in other structures of the joint, [45] we shall focus on ligament injury initiated or derived $\mathrm{OA}$ in the section below. There are several reasons for this focus:

(1) Chronic musculoskeletal pain can be caused primarily by ligamentous laxity, or enthesopathy; the painful muscle spasms and trigger points associated with them are secondary and appear as late sequelae of ligamentous laxity and resultant joint instability [15].

(2) There is emerging evidence from recent scientific findings that the mechanism of ligament injury-derived OA begins with ligament injury and the subsequent changes in ligament mechanics and biochemistry that renders the joint unstable $[35,52,53]$.

(3) It has been reported that OA is best modeled as a disease of organ failure, in which injury to one joint constituent leads to damage of other components, and collectively results in joint failure and the clinical manifestations of OA [54, 55]. Indeed, published reports indicate that ligament injury induces damage to the entire joint; synovitis, effusions and hematoma are associated with ligament injury and are known to affect articular cartilage, the subchondral bone, the injured ligament, and other soft tissue structures in the given joint [35] (See Fig. 4). Recently, Andriacchi et al. described a possible mechanical mechanism for the onset and progression of osteoarthritis based on ligament injury [56].

(4) Joint laxity and instability as a result of ligament deterioration or rupture have long been considered to be a strong contributor to the development of post-traumatic osteoarthritis [57-61].

(5) A structural model of OA provides a useful reference framework for a focused understanding of the magnitude of disease in the same way that tumors can be classified and staged according to their tissue of origin and extent of involvement. Moreover, this approach has implications for therapeutic strategies (for example, regenerative medicine therapy schemes targeted to specific structural locations of the joint) $[44,62]$.

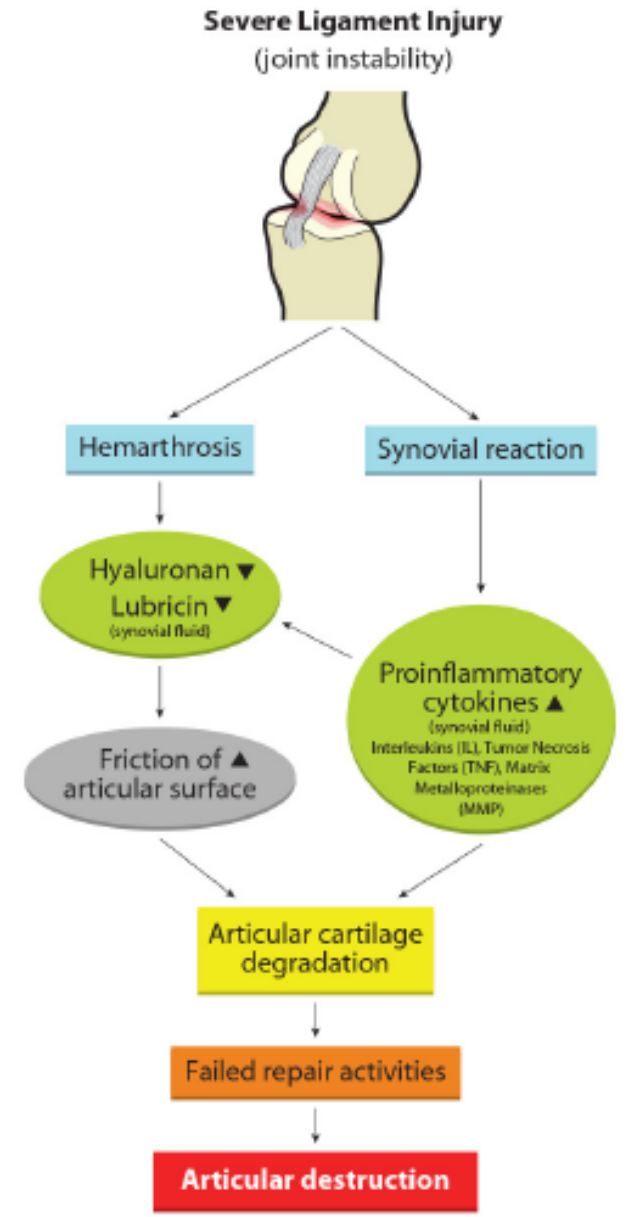

Fig. (4). Mechanisms underlying the development of posttraumatic osteoarthritis after ligament injury. Although the initial pathological changes may vary depending on the damage to specific joint tissues, these changes eventually lead to articular cartilage degradation and joint destruction. The synovium and articular cartilage can interact with each other through specific mediators in synovial fluid, which are secreted by either chondrocytes or synoviocytes. The acute hemarthrosis after injury eventually resolves, but the synovial reaction continues indefinitely until joint stability is restored. Modified and used with permission from: Kramer WC, et al. Pathogenetic mechanisms of posttraumatic osteoarthritis: opportunities for early intervention. Int $\mathrm{J}$ clin Exp Med 2011; 4(4): 285-98.

\section{Ligament Mechanoreceptors Involvement in Inflammation, Osteoarthritis and Pain Sensing}

Ligaments in joints and the spine are endowed with mechanoreceptors, including pancinian, golgi, ruffini and bare nerve endings. (Fig. 5). By virtue of their innervation, ligaments also play an important role in proprioception and kinesthesia, and have a direct role in reflex activation or inhibition of muscular activities to preserve joint stability [63]. There is increasing evidence that some ligaments and/or the joint capsules that reinforce joints can have complex functional interactions with adjacent bone surfaces and with other joint tissues near their entheses, forming part of an enthesis organ and synovio-entheseal complex [44, 6466]. The enthesis has been shown to be a dynamic area metabolically active, endowed with a rich vascular supply, 
and highly innervated, particularly with $\mathrm{C}$ and $\mathrm{A} \boldsymbol{\delta}$ pain fibers [23]. Thus, where a tendon/ligament contacts a bone immediately adjacent to its enthesis, the intermittent compressive loading may be sufficiently high to provoke a chondrogenic metaplasia near the interface of the two contacting tissues.

\section{Ligaments as a Sensory Organ}

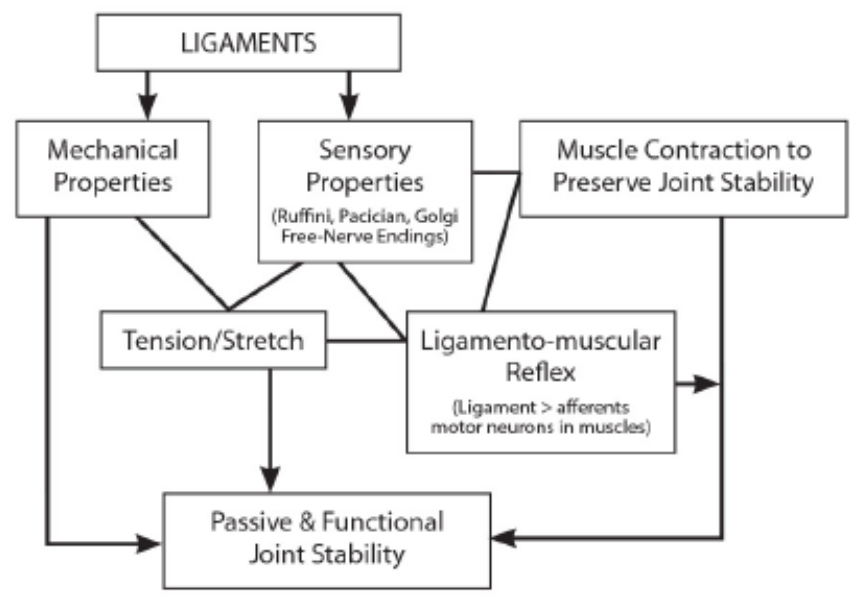

Fig. (5). Ligaments as a sensory organ. Basic organizational plan adapted from: Johansson H, Sojka P. A sensory role for the cruciate ligaments. Clinical Orthopaedics and Related Research 1991; 268: $161-78$.

In view of the structural and physiological characteristics of the ligaments and their entheses, an exaggerated response to an insult can occur. This anatomical arrangement may be key to the development of the OA phenotype $[67,68]$. The imbalance between the breakdown and repair of joint tissues in $\mathrm{OA}$ is the result of the activation of joint cells by inflammatory mediators, matrix components and mechanical stress [69]. A number of putative mediators have been implicated in the catabolic process, including matrixdegrading proteases, superoxide radicals and proinflammatory cytokines [70]. Counterbalancing this, insulin growth factor (IGF-1), transforming growth factor (TGF)-b and bone morphogenetic proteins (BMPs) are endogenous anabolic factors that stimulate bone and cartilage regeneration and remodeling [71, 72]. Thus, it is now becoming clear that primary changes in ligaments and their insertions can profoundly affect the adjacent bone and synovial tissues [44]. At the macroscopic level, inflammation is directly linked to clinical symptoms such as joint swelling, synovitis and inflammatory pain. Structural joint instability from injuries to ligaments results in an inflammatory reaction that initiates a chemical cascade in and around the joint characteristic of most injured tissues. [23]. The collateral ligaments appear to be at the epicenter of the inflammatory process and their involvement explains the periarticular pattern of inflammation evident in hand $\mathrm{OA}$ $[47,48,73]$.

\section{Current Standards of Treatment and Management for Optimizing Ligament Repair and Healing}

Ligament healing is generally slow and often incomplete. Joint laxity caused by ligament injury improves slowly, often over several weeks to a year or more, after which a large percentage of patients still have objective mechanical laxity and subjective joint instability [28, 74]. Several standard, novel/biotechnological and complementary alternative medicine (CAM) treatment and management strategies have been implemented over the years in attempt to heal and restore the structural and functional properties of injured ligaments to pre-injury status. Available treatments include, over the counter (OTC) medications [analgesics, nonsteroidal anti-inflammatory drugs (NSAIDs), corticosteroid and hyaluronate (viscosupplementation) injections, narcotics/opioids, anti-depressants, muscle relaxants, sedatives, physical therapy and exercise, rest and mobilization, diet and nutrition, surgery (arthroscopy, ligament reconstruction, debridement, fusion, arthroplasty), acupuncture, and chiropractic manipulation [28, 75-86].

While each of these therapies may help to temporarily alleviate the subjective symptom of acute or chronic joint pain following ligament injury, they do not all address damage to the ligaments, resultant instability, of the joint or contribute to the actual cellular repair and healing processes of ligament tissue. In fact, some of these therapies (NSAIDs and corticosteroids) have been shown to be detrimental to the ligament healing process because these drugs suppress and inhibit certain cellular processes that are required for ligament tissue repair and healing. Analgesics can also have some very serious adverse side effects on the patient (such as hepato-toxicity and potential renal damage). Narcotics not only alter the neuropsychological and pathophysiological responses of the body, but also suppress both innate and adaptive immune function [24, 26, 87]. Other therapies (e.g., prolotherapy) have been shown to contribute to repair and healing through stimulation of certain cellular processes involved in the regeneration of ligament tissue. In the following subsections, we shall briefly discuss the effectiveness of two of the main therapies used for chronic musculoskeletal pain: NSAIDs and corticosteroids, as well as prolotherapy in repairing and healing injured ligaments.

\section{Nonsteroidal Anti-inflammatory Drugs (NSAIDs)}

Nonsteroidal anti-inflammatory drugs (NSAIDs) have been a mainstay treatment in ligament injuries for several years, especially in the case of acute sports injuries. However, new research has shown that these antiinflammatory drugs are only mildly effective in relieving the symptoms of most ligament, tendon and muscle injuries and are potentially deleterious to soft tissue healing [88, 89]. There are valid reasons to expect that NSAIDs might have an adverse effect on healing, since prostaglandin-induced inflammation is an early sequel in the cascade of the healing of injury induced events. This response normally results in the recruitment of cells into the injured area where they remove necrotic debris and initiate the healing process. However, NSAIDs are known to specifically block the cyclooxygenase enzymes, which catalyze the conversion of arachidonic acid to prostaglandins that would otherwise play a significant role in ligament healing [90]. Additionally, because of the analgesic effect of NSAIDs, patients may feel no discomfort while doing strenuous activities and ignore early symptoms of ligament injury, which could cause further damage to the ligament, and thus, delay definitive healing. 
Multiple studies have been conducted on the cyclooxygenase-2 (COX-2) inhibitor class of NSAIDs, and researchers have concluded that the use of these medications inhibits ligament healing and leads to impaired mechanical strength [91, 92]. Therefore, NSAIDs are no longer recommended for chronic soft tissue (ligament) injuries. In the case of acute ligament injuries, NSAIDs should be used for the shortest period of time possible, if used at all $[93,94]$.

\section{Cortisone Injections}

Corticosteroid injections have also been a long-standing treatment regimen for musculoskeletal disorders, including ligament injuries. Although steroid injections have been shown to be effective in decreasing inflammation and pain in ligament injuries for up to six to eight weeks, they inhibit the histological, biochemical, and biomechanical properties of ligament healing. While the anti-inflammatory actions of corticosteroids stem from their ability to prevent lysosomal enzyme release, this also inhibits neutrophils and other inflammatory cells from accumulating at the injury site, as well as disrupts the synthesis of cytokines and other inflammatory mediators [95]. This impedes the normal repair processes that are stimulated after normal joint trauma and injury $[95,96]$.

Further evidence that corticosteroid injections into injured ligaments have an adverse effect on healing has become known. Corticosteroid injections into ligaments and tendons can inhibit fibroblast function and thus collagen synthesis [96, 97], even to the extent of causing collagen necrosis at the injection site [98]. Given the inhibitory effects corticosteroid injections have on ligament healing, reviews have cautioned against their use for treating ligament injuries, especially in athletes [28, 99].

\section{Application of Prolotherapy Biology for the Healing of Injured Ligaments}

The healing phases and the biomechanical consequences of ligament injury have been previously discussed in brief. Fig. (6) is a schematic depiction of the application of the therapeutic principle of prolotherapy - encompassing the inflammatory, proliferation and tissue remodeling phases of the healing and restoration processes of injured ligaments/tendons. The mechanism of action behind prolotherapy is not completely understood; however, modern theory suggests the injected proliferants mimic the natural healing process by initiating a local inflammatory response, which triggers or signals a healing cascade that releases growth factors and collagen deposition. This process leads to proliferation, ligament tissue remodeling, strengthening of new tissue, joint stability and reduction in pain and dysfunction [100, 101].

Most human cells contain only $0.1 \%$ dextrose. However, in vitro studies on human fibroblasts and chondrocytes demonstrate stimulation of growth factors when cells are exposed to dextrose concentrations of only $0.5 \%[102,103]$. These growth factors include platelet-derived growth factor,

\section{The Biology of Prolotherapy}
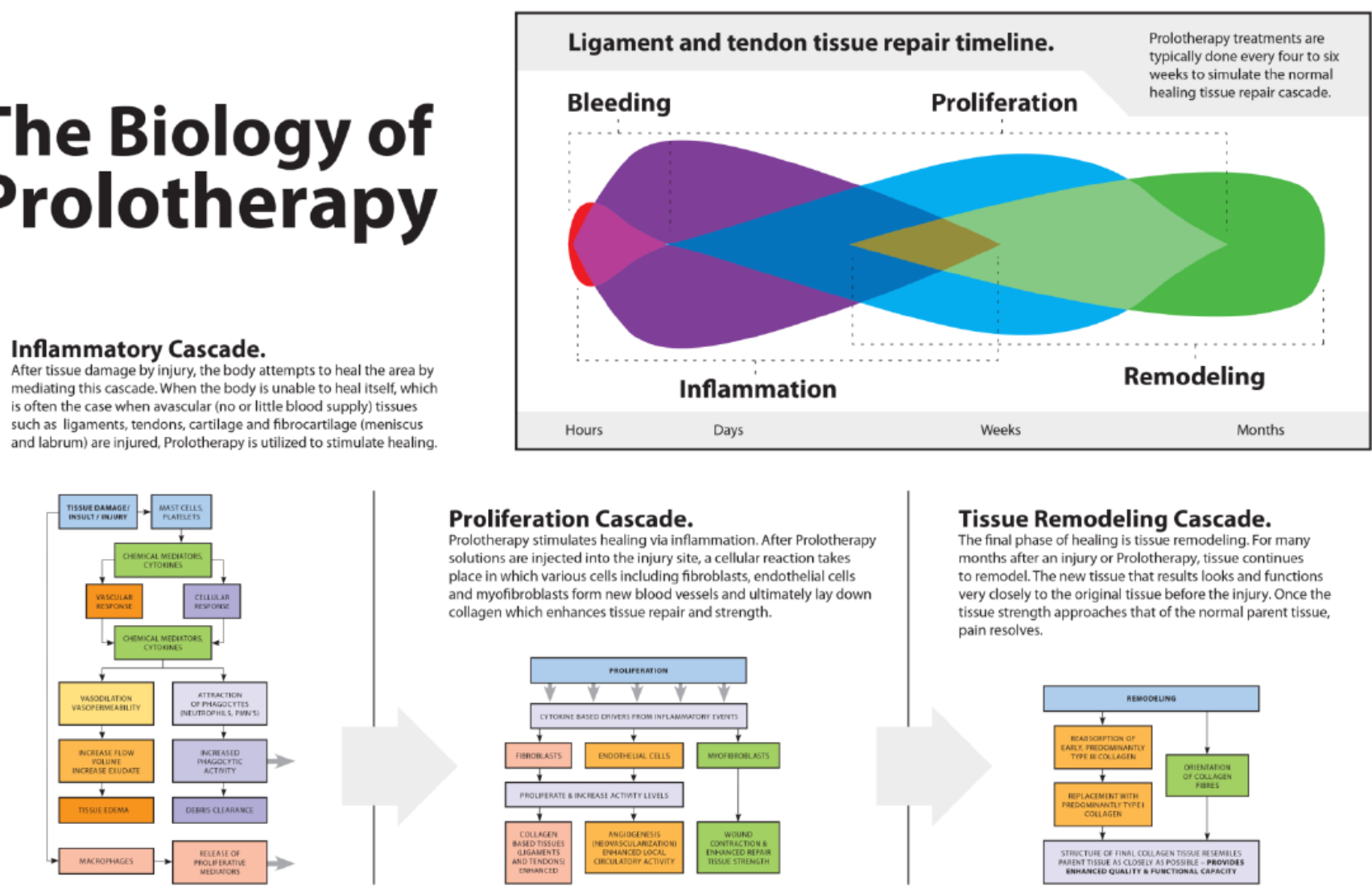

Fig. (6). The biology of prolotherapy. Prolotherapy induces the three stages of healing and restoration: inflammatory, proliferation, and tissue remodeling. 
transforming growth factor- $\beta$, epidermal growth factor, basic fibroblast growth factor, insulin-like growth factor, and connective tissue growth factor-having been found in vitro to promote the expression of type 1 and 3 collagen in tenocytes, and are pertinent to the formation and growth of ligament, tendon and cartilage [104-107]. Prolotherapy solutions that contain concentrations less than $10 \%$ dextrose are known to be non-inflammatory, while those greater than $10 \%$ are inflammatory $[19,100]$. In summary, an increase of glucose concentration (dextrose) with Prolotherapy causes an increase in cell protein synthesis, DNA synthesis, cell volume, and proliferation [108]. Thus, simple dextrose solution is an inexpensive method of growth stimulation that may prove to be cost-effective for the treatment and longterm management of diverse musculoskeletal joint-related pain [106].

Several molecules have been recognized as potential proliferants and it has been suggested that the mechanism of action by which they induce local, controlled inflammation might vary depending on the type of substance. Theoretically, the main proliferants have been classified into three groups based on their possible biochemical mechanisms as irritants, osmotics, and chemotactics [10, 109]. The osmotic shock agents, such as concentrated dextrose, zinc and glycerin solutions, are believed to act by dehydrating cells at the injection site. This leads to local tissue trauma, which, in turn, attracts granulocytes and macrophages. The most common prolotherapy agents used in clinical practice are dextrose solutions ranging from $12.5 \%$ $25 \%$ [107]. Dextrose proliferant has been approved for injection by FDA, but not for prolotherapy; thus, it is currently used in prolotherapy as an off-label substance [11]. Phenol, guaiacol, and pumic acid belong to the second class known as irritants and are thought to act directly damaging cell membranes. Chemotactic agents, such as polidocanol and sodium morrhuate are purported to be direct chemotactic agents to inflammatory cells. Newer forms of prolotherapy termed "cellular prolotherapy" involve using a person's own cells as the proliferant and include whole blood, platelet rich plasma, bone marrow and adipose tissue [109-111].

\section{Effective Applications of Prolotherapy in the Treatment of Chronic Musculoskeletal Conditions}

Prolotherapy injections stimulate ligament size and mass, tendon hypertrophy, extracellular matrix, fibroblastic proliferation, increased ligament-bone junction strength and repair of articular cartilage defects [19, 108, 112]. Prolotherapy has been utilized for the following groups of conditions including: degenerative arthritis; enthesopathies; ligament injury; tendinopathy, including tendinosis and tendinitis; joint instability from a myriad of causes including ligament, labrum or meniscus injury and a host of other conditions with a few of them discussed in the following sections [108, 113-116].

Osteoarthritis - Rabago et al. conducted a randomized controlled trial of dextrose prolotherapy in the treatment of symptomatic chronic knee OA [13, 117, 118]. The 3-arm, blinded (injector, assessor, injection group participants) were randomized to blinded injection with dextrose or saline which were compared, along with a control group that did athome exercises. Outcomes were assessed by the validated
Western Ontario McMaster University Osteoarthritis Index (WOMAC; 100-point scale) at 52 weeks. In this trial, WOMAC scores among dextrose prolotherapy recipients were more improved at 52 weeks than scores among saline control and at-home exercise participants (mean [SD] score change, 15.3 [3.5] vs 7.6 [3.4] and 8.2 [3.3], respectively; $P<.05)$ [118].

Additional evidence of the efficacy of dextrose prolotherapy in the treatment of osteoarthritis was demonstrated by Reeves et al. The authors conducted two studies that examined the treatment of knee, and finger and thumb osteoarthritis in patients with at least 6 months of associated pain and radiographic evidence of significant joint space narrowing, a moderate sized osteophyte, or both in at least one compartment of the affected joint space. Participants in both studies were randomized to receive either dextrose and lidocaine, or lidocaine and bacteriostatic water injections, at 0,2 , and 4 months. Compared to control groups, subjects in the experimental groups in both studies showed positive outcomes, with improvement in pain at rest and with activity, joint stabilization, and improved range of motion. However, neither study's results achieved statistical significance [119]. Interestingly, blinded radiographic readings at 0 and 12 months revealed improvement in lateral patellofemoral cartilage thickness and distal femur width. Three-year follow up data also showed improvements in pain during walking, subjective reports of decreased swelling and increased range of motion in the group treated with dextrose.

Chronic Tendinopathies - Tendinopathy refers to a painful clinical condition that occurs often as a result of overuse. Prolotherapy has been used clinically for multiple types of tendinopathy (Fig. 7) and has been studied for the treatment of lateral epicondylosis, Achilles tendinopathy, plantar fasciitis and hip adductor tendinopathies [100]. In a single-blind randomized controlled trial comparing dextrose and dextrose-sodium morrhuate prolotherapy to a control group with chronic lateral epicondylosis; both prolotherapy groups showed improved grip strength compared to the wait and see group at 16 weeks $(\mathrm{P}<0.05)$. Both prolotherapy groups reported improved composite patient-rated tennis elbow evaluation scores [120]. In a double-blind randomized control trial of 20 adults with refractory lateral epicondylosis, the dextrose-sodium morrhuate group, compared to controls, reported statistically significant improvements in pain scores and grip strength that persisted at 52 weeks [121].

Maxwell et al. used ultrasound guidance to provide intratendinous injections of a dextrose and anesthetic solution to 36 adults with chronic, refractory Achilles tendinopathy at 6-week intervals. The researchers reported statistically significant reductions in pain scores at 6 weeks as well as decreased neovascularity as measured by ultrasound in $55 \%$ of the tendons [113]. Another study showed that dextrose prolotherapy in combination with eccentric loading exercises provided the most relief in the first 6 weeks in the management of Achilles tendinopathy compared with prolotherapy or exercises alone. However, the study yielded no significant difference between the treatment groups at 12 months [122].

A case series examined the efficacy of prolotherapy on hip adductor tendinopathy in male athletes engaged in 


\section{The Histology of How Prolotherapy Heals}

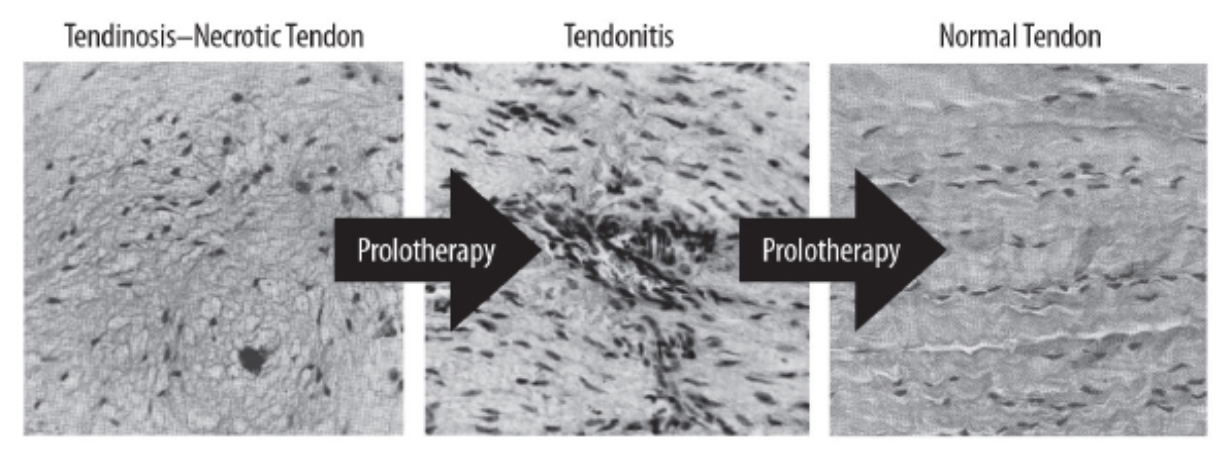

Fig. (7). Prolotherapy for tendinosis: histology samples. Used with permission from Overuse Injuries of the Musculoskeletal System Marko M. Peling, CRC Press, 1993, Boca Raton, FL.

kicking sports. Subjects with groin pain for a mean of 15.5 months that was unresponsive to specified physical therapy were injected monthly with dextrose and lidocaine into the areas of maximal tenderness. The average number of injections given was 2.8. Twenty of 24 athletes had complete resolution of painful symptoms, and nearly all the participants were able to return to their sport without restrictions as measured by pain and functional scales [123].

A pilot study by Ryan et al. examined the effects of prolotherapy on chronic plantar fasciopathy in patients who had failed conservative treatments. The researchers injected 36 symptomatic adults with hyperosmolar dextrose and lidocaine solution under ultrasound guidance. They then used visual analog scales for pain at rest, during activities of daily living, and during or after physical activity. Researchers reported significantly decreased mean scores in all areas at the final treatment consultation [124].

Dysfunctional Sacroiliac Joint - Use of prolotherapy for treatment of sacroiliac joint dysfunction has also been demonstrated to be effective. Cusi et al. used computed tomography to guide injections of hyperosmolar dextrose into painful, dysfunctional sacroiliac joints in 25 patients. The authors reported significant improvement in pain and disability scores compared to baseline scores; however, there were no control subjects used in this study [114]. A similar study compared the effects of hyperosmolar dextrose versus triamcinolone acetonide fluoroscopically guided intraarticular injections into painful sacroiliac joints. Results demonstrated improvements in pain and disability scores from baseline in both groups; however, the effects of the dextrose group lasted longer than the steroid group [125]. In another study, intraarticular dextrose prolotherapy to the sacroiliac joint gave significant improvements in the numeric rating scale and Oswestry Disability Index compared to baseline $(\mathrm{p}<0.01)$ [126].

Chronic Coccygodynia and Other Chronic Musculoskeletal Conditions - Khan and his group studied 37 patients with chronic coccygodynia. The patients received up to three dextrose-lidocaine injections into the coccyx. Thirty of the 37 patients had improved visual analog scores [127]. Numerous other studies including case reports have documented success in utilizing prolotherapy in the treatment of chronic musculoskeletal pain $[107,115,116$, 128-136]. These studies offer promise for prolotherapy for a host of conditions and support the need for further RCTs aimed at more precise indications with this approach.

\section{CONCLUDING REMARKS}

The most frequently reported chronic pain conditions are associated with musculoskeletal dysfunction and degeneration. One primary cause of this is joint instability from ligament injury, which is hampered by standard therapeutics such as NSAIDs and corticosteroid injections. The degenerative process associated with weak and unstable joints can be slowed and potentially prevented by treatment with prolotherapy. If treated in the early stages, the proliferation of new ligament tissue strengthens the joint and helps restore proper joint mechanics and smooth/frictionless joint motion. By decreasing laxity of the ligaments and instability of the joint, contact forces can be redistributed back onto the areas of thickest cartilage that are designed to handle high loads and reduce the stress at thinner, weaker points, preventing deleterious biochemical and biomechanical events in the joint and allow healing to take place. Even in later stages of degeneration and OA, improvements in pain, instability and function are possible as amply described in the published literature. For some patients, prolotherapy is the treatment of choice for ligament injuries (sprains, tears, instability, and benign hypermobility syndrome) and the resultant cartilage degeneration they cause [24].

Prolotherapy is an old and respected technique of alternative musculoskeletal pain treatment that has its place in comprehensive musculoskeletal joint pain and joint instability management. Careful patient selection with attention to individual anatomy, course of disability and pain, level of functional impairment, and identification of patient treatment goals are the best starting points for determining the appropriateness of prolotherapy. In some cases, prolotherapy as a solo treatment modality might not be sufficiently effective to completely alleviate chronic musculoskeletal pain, ligament/tendon injury, or joint osteoarthritis. However, when combined with a carefully planned and individualized, integrative pain management program, prolotherapy is a very valuable addition to standard or CAM methods.

Although the results of the cited studies indicate good promise for dextrose prolotherapy in the treatment of 
musculoskeletal pain and joint instability, additional comparative effectiveness studies need to be conducted which include biomechanical and imaging outcome measures to assess potential disease modification in order to definitively determine the clinical utility of prolotherapy. As more research into joint instability and effective healing is obtained and well-designed clinical studies are performed confirming current understanding of the beneficial effects of prolotherapy, it will likely become more acceptable by mainstream medical practitioners, and available to vast numbers of people who suffer from the disabling effects of chronic musculoskeletal pain $[24,69]$.

\section{CONFLICT OF INTEREST}

The authors declared the following potential conflicts of interest with respect to the research, authorship, and/or publication of this article: $\mathrm{RH}, \mathrm{PB}$, and DS perform prolotherapy in their practices.

\section{ACKNOWLEDGEMENTS}

This work was supported in part by the U.S. Department of Defense (DoD) medical research grant \# W81XWH-12-10304 (to J. Wang).

\section{PATIENT'S CONSENT}

Declared none.

\section{REFERENCES}

[1] The Joint Commission. Facts about pain management. Available at: www.jointcommission.org/assets/1/18/Pain_Management.pdf

[2] Portnoy RK, Zelter L. A call to revolutionize chronic pain care in America: An opportunity in health care reform. The Mayday Fund. November 4, 2009. Available at: www.maydaypainreport.org

[3] Murray CJL, Vos T, Lozano R, et al. Disability-adjusted life years (DALYs) for 291 diseases and injuries in 21 regions, 1990-2010: A systematic analysis for the Global Burden of Disease Study 2010. Lancet 2012; 380: 2197-223.

[4] The Burden of Musculoskeletal Diseases in the United States: Prevalence, Economic and Societal Cost, $2^{\text {nd }}$ Ed. Rosemont (IL): Academy of Orthopaedic Surgeons; 2011. Available from: http://www.boneandjointburden.org/pdfs/BMUS_IntroPrefaceFore word.pdf [Accessed 20 June 2014].

[5] Institute of Medicine (IOM). Relieving pain in America: A blueprint for transforming prevention, care, education, and research. Washington, DC: The National Academies Press 2011.

[6] Tsang A, Von Korff M, Lee S, et al. Common chronic pain conditions in developed and developing countries: gender and age differences and comorbidity with depression-anxiety disorders. J Pain 2008; 9(10): 883-91.

[7] IASP, 1994. Part III: Pain Terms, A Current List with Definitions and Notes on Usage (pp 209-214). Classification of Chronic Pain, $2^{\text {nd }}$ Edition, IASP Task Force on Taxonomy, edited by H. Merskey and N. Bogduk, ISAP Press, Seattle, 1994. http://www.iasppain.org

[8] Baer AN. The approach to the painful joint. Available at: http://emedicine.medscape.com/article/336054-overview

[9] Hackett G, Hemwall G, Montgomery G. Ligament and tendon relaxation treated by prolotherapy. $5^{\text {th }}$ ed. Oak Park (IL): Beulah Land Press 1991.

[10] Nair LS. Prolotherapy for tissue repair. Translational Res 2011; 158(3): 129-31.

[11] Adams E. Bibliography: Prolotherapy for musculoskeletal pain. Boston, MA: Veterans Administration Technology Assessment Program (VATAP); April 2008.

[12] Rabago D, Slattengren A, Zgierska A. Prolotherapy in primary care practice. Prim Care 2010; 37(1): 65-80.
[13] Rabago D, Patterson JJ. Prolotherapy: An effective adjunctive therapy for knee osteoarthritis. J Am Osteopath Assoc 2013; 113(2): 122-3.

[14] Polukhin E. Prolotherapy, myths and the truth. Altern Integ Med 2013; 2(3): 114.

[15] Hackett G. Low back pain. Br J Phys Med 1956; 19: 25-35.

[16] Hackett G. Back pain following trauma and disease - prolotherapy. Milit Med 1961; 5: 17-25.

[17] Dagenais S, Yelland MJ, Del Mar C, Schoene ML. Prolotherapy injections for chronic low-back pain. Cochrane Database Syst Rev 2007; (2): CD004059.

[18] Jansen JA, Mens JM, Backx FJ, Kolfschoten N, Stam HJ. Treatment of longstanding groin pain in athletes: A systematic review. Scand J Med Sci Sports 2008; 18: 263-74.

[19] Jensen KT, Rabago DP, Best TM, Patterson JJ, Vanderby R Jr. Response of knee ligaments to prolotherapy in a rat injury model. Am J Sports Med 2008; 36: 1347-57.

[20] Saladin KS. Joints in Human Anatomy, $3^{\text {rd }}$ ed., McGraw-Hill Higher Education, 2011.

[21] Frank CB. Ligament structure, physiology and function. J Musculoskel Neuron Interact 2004; 4(2): 199-201.

[22] Savio LYW, Steven DA, Robert K, Rui L. Biomechanics of knee ligaments: injury, healing, and repair. J Biomechanics 2006; 39: 120.

[23] Palesy PD. Tendon and ligament insertions - a possible source of musculoskeletal pain. Cranio 1997; 15(3): 194-202

[24] Wheaton MT, Jensen N. The ligament injury-osteoarthritis connection: The role of prolotherapy in ligament repair and the prevention of osteoarthritis. J Prolotherapy 2011; 3(4): 790-812.

[25] The Diagnosis and management of soft tissue knee injuries: Internal derangements. Best practice evidence-based guideline. New Zealand 2002.

[26] David J. Hunter Osteoarthritis. Best Pract Res Clin Rheumatol 2011; 25: 801-14.

[27] Frobell RB, Roos HP, Roos EM, et al. The acutely ACL injured knee assessed by MRI: Are large volume traumatic bone marrow lesions a sign of severe compression injury? Osteoarthr Cartil 2008; 16: 829-36.

[28] Hauser RA, Dolan EE, Phillips HJ, Newlin AC, Moore RE, Woldin BA. Ligament injury and healing: A review of current clinical diagnostics and therapeutics. Open Rehab J 2012; 5: 48-66.

[29] Flynn RK, Pedersen CL, Birmingham TB, Kirkley A, Jackowski D, Fowler PJ. The familial predisposition toward tearing the anterior cruciate ligament: A case control study. Am J Sports Med 2005; 33: 23-8.

[30] Yelin E, Callahan LF. The economic cost and social and psychological impact of musculoskeletal conditions. National Arthritis Data Work Groups. Arthritis Rheum 1995; 38: 1351-62.

[31] Schepsis AA, Busconi BD, eds. Sports Medicine. Pennsylvania: Lippincott Williams \& Wilkins 2006: p. 18.

[32] Woo SL, Debski RE, Zeminski J, Abramowitch SD, Saw SS, Fenwick JA. Injury and repair of ligaments and tendons. Annu Rev Biomed Eng 2000; 2: 83-118.

[33] Jung HJ, Fisher MB, Woo SL. Role of biomechanics in the understanding of normal, injured and healing ligaments and tendons. Sports Med Arthrosc Rehabil Ther Technol 2009; 1(1): 9.

[34] Loitz-Ramage BJ, Frank CB, Shrive NG. Injury size affects longterm strength of the rabbit medial collateral ligament. Clin Orthop Relat Res 1997; (337): 272-80.

[35] Fleming BC, Hulstyn MJ, Oksendahl HL, Fadale PD. Ligament injury, reconstruction, and osteoarthritis. Curr Opinion Orthop 2005; 16(5): 354-62.

[36] Panjabi MM. A hypothesis of chronic back pain: Ligament subfailure injuries lead to muscle control dysfunction. Eur Spine $\mathrm{J}$ 2006; 15(5): 668-76.

[37] Schmitt LC, Fitzgerald GK, Reisman AS, Rudolph KS. Instability, laxity, and physical function in patients with medial knee osteoarthritis. Phys Ther 2008; 88(12): 1506-16.

[38] Koh J, Dietz J. Osteoarthritis in other joints (hip, elbow, foot, toes, wrist) after sports injuries. Clin Sports Med 2005; 24: 57-70.

[39] Lohmander LS, Ostenberg A, Englund M, Roos H. High prevalence of knee osteoarthritis, pain, and functional limitations in female soccer players twelve years after anterior cruciate ligament injury. Arthritis Rheum 2004; 50(10): 3145-52. 
[40] van der Esch M, Steultjens M, Knol DL, Dinant H, Dekker J. Joint laxity and the relationship between muscle strength and functional ability in patients with osteoarthritis of the knee. Arthritis Care Res 2006; 55(6): 953-9.

[41] Arden N, Nevitt MC. Osteoarthritis: Epidemiology. Best Pract Res Clin Rheumatol 2006; 20(1): 3-25.

[42] McGonagle D, Tan AL, Grainger AJ, Benjamin M. Heberden's nodes and what Heberden could not see: The pivotal role of ligaments in the pathogenesis of early nodal osteoarthritis and beyond. Rheumatology 2008; 47(9): 1278-85.

[43] Brandt KD, Radin EL, Dieppe PA, van de Putte L. Yet more evidence that osteoarthritis in not a cartilage disease. Ann Rheum Dis 2006; 65: 1261-4.

[44] McGonagle D, Tan AL, Carey J, Benjamin M. The anatomical basis for a novel classification of osteoarthritis and allied disorders. J Anat 2010; 216: 279-91.

[45] Krasnokutsky S, Attur M, Palmer G, Samuels J, Abramson SB. Current concepts in the pathogenesis of osteoarthritis. Osteoarth Cartil 2008; 16 (Suppl 3): S1-3.

[46] Rogers J, Shepstone L, Dieppe P. Is osteoarthritis a systemic disorder of bone? Arthritis Rheum 2004; 50(2): 452-7.

[47] Tan AL, Grainger AJ, Tanner SF, et al. High-resolution magnetic resonance imaging for the assessment of hand osteoarthritis. Arthritis Rheum 2005; 52(8): 2355-65.

[48] Tan AL, Toumi H, Benjamin M, et al. Combined high resolution magnetic resonance imaging and histological examination to explore the role of ligaments and tendons in the phenotypic expression of early hand osteoarthritis. Ann Rheum Dis 2006; 65(10): 1267-72.

[49] Conaghan P. Is MRI useful in osteoarthritis? Best Pract Res Clin Rheumatol 2006; 20(1): 57-68.

[50] Louboutin H, Debarge R, Richou J, et al. Osteoarthritis in patients with anterior cruciate ligament rupture: A review of risk factors. Knee 2009; 16: 239-44.

[51] Øiestad BE, Engebretsen L, Storheim K, Risberg MA. Knee osteoarthritis after anterior cruciate ligament injury. Am J Sports Med 2009; 37(7): 1434-343.

[52] Quasnichka HL, Anderson-MacKenzie JM, Tarlton JF, Sims TJ, Billingham ME, Bailey AJ. Cruciate ligament laxity and femoral intercondylar notch narrowing in early-stage knee osteoarthritis. Arthritis Rheum 2005; 52(10): 3100-9.

[53] Yeow CH, Cheong CH, Ng KS, Lee PV, Goh JC. Anterior cruciate ligament failure and cartilage damage during knee joint compression: A preliminary study based on the porcine model. Am J Sports Med 2008; 36: 934-42.

[54] Al-Sharqi SAH, Wahab MS, Hussainy SKD. Histopathological study in posterior cruciate ligament of osteoarthritis and rheumatoid arthritis in Iraqi patients. Am J Med and Medical Sci 2013; 3(1): 10-6.

[55] Peterfy CG, Guermazi A, Zaim S, et al. Whole-organ magnetic resonance imaging score (WORMS) of the knee in osteoarthritis. Osteoarthritis Cartilage 2004; 12: 177-90.

[56] Andriacchi TP, Mundermann A, Smith RL, Alexander EJ, Dyrby $\mathrm{CO}$, Koo S. A framework for the in vivo pathomechanics of osteoarthritis at the knee. Ann Biomed Eng 2004; 33: 447-57.

[57] Heijink A, Gomoll AH, Madry $\mathrm{H}$, et al. Biomechanical considerations in the pathogenesis of osteoarthritis of the knee. Knee Surg Sports Traumatol Arthrosc 2012; 20: 423-35.

[58] Frobell RB, Lohmander LS, Roos HP. Acute rotational trauma to the knee: Poor agreement between clinical assessment and magnetic resonance imaging findings. Scand J Med Sci Sports 2007; 17: 109-14.

[59] Lohmander LS, Englund PM, Dahl LL, Roos EM. The long-term consequence of anterior cruciate ligament and meniscus injuries: osteoarthritis. Am J Sports Med 2007; 35: 1756-69.

[60] Lohmander LS, Ostenberg A, Englund M, Roos H. High prevalence of knee osteoarthritis, pain, and functional limitations in female soccer players twelve years after anterior cruciate ligament injury. Arthritis Rheum 2004; 50: 3145-52.

[61] Von PA, Roos EM, Roos H. High prevalence of osteoarthritis 14 years after an anterior cruciate ligament tear in male soccer players: A study of radiographic and patient relevant outcomes. Ann Rheum Dis 2004; 63: 269-73.
[62] Ash Z, McGonagle D. Joint appendages: The structures which have historically been overlooked in arthritis research and therapy development. Best Pract Res Clin Rheumatol 2011; 25(6): 779-84.

[63] Solomonov M. Ligaments: A source of musculoskeletal disorders. J Bodyw Mov Ther 2009; 13: 136-54.

[64] Frank CB. Ligament structure, physiology and function. J Musculoskel Neuron Interact 2004; 4(2): 199-201.

[65] McGonagle D, Lories RJ, Tan AL, Benjamin M. The concept of a "synovio-entheseal complex" and its implications for understanding joint inflammation and damage in psoriatic arthritis and beyond. Arthritis Rheum 2007; 56(8): 2482-91.

[66] Benjamin M, McGonagle D. Histopathologic changes at "synovioentheseal complexes" suggesting a novel mechanism for synovitis in osteoarthritis and spondylarthritis. Arthritis Rheum 2007; 56(11): 3601-9.

[67] Grainger AJ, Farrant JM, O'Connor PJ, et al. MR imaging of erosions in interphalangeal joint osteoarthritis: Is all osteoarthritis erosive? Skeletal Radiol 2007; 36(8): 737-45.

[68] McGonagle D, Tan AL, Moller Dohn U, Ostergaard M, Benjamin M. Microanatomic studies to define predictive factors for the topography of periarticular erosion formation in inflammatory arthritis. Arthritis Rheum 2009; 60: 1042-51.

[69] Berenbaum F. Signaling transduction: Target in osteoarthritis. Curr Opin Rheumatol 2004; 16: 616-22.

[70] Haringman JJ, Ludikhuize J, Tak PP, Haringman JJ, Ludikhuize J, Tak PP. Chemokines in joint disease: the key to inflammation? Ann Rheum Dis 2004; 63: 1186-94.

[71] Fan Z, Chubinskaya S, Rueger DC, et al. Regulation of anabolic and catabolic gene expression in normal and osteoarthritic adult human articular chondrocytes by osteogenic protein-1. Clin Exp Rheum 2004; 22: 103-6.

[72] Lajeunesse D. The role of bone in the treatment of osteoarthritis. Osteoarthr Cartil 2004; 12(Suppl A): 34-8.

[73] McGonagle D, Tan AL, Grainger AJ, Benjamin M. Heberden's nodes and what Heberden could not see: The pivotal role of ligaments in the pathogenesis of early nodal osteoarthritis and beyond. Rheumatology (Oxford) 2008; 47: 1278-85.

[74] Hubbard TJ, Hicks-Little CA. Ankle ligament healing after an acute ankle sprain: An evidence-based approach. J Athletic Training 2008; 43(5): 523-9.

[75] Stein A, McAleer S, Hinz M. Microperforation prolotherapy: a novel method for successful nonsurgical treatment of atraumatic spontaneous anterior sternoclavicular subluxation, with an illustrative case. Open Access J Sport Med 2001; 2: 47-52.

[76] Mammucari M, Gatti A, Maggiori S, Sabato AF. Role of mesotherapy in musculoskeletal pain: Opinions from the Italian society of mesotherapy. Evid Based Complement Alternat Med 2012; 436959. Available From: http://www.ncbi.nlm.nih.gov/pmc/ articles/PMC3359685/

[77] Jones P, Lamdin R. Oral cyclo-oxygenase 2 inhibitors versus other oral analgesics for acute soft tissue injury: Systematic review and meta-analysis. Clin Drug Investig 2010; 30(7): 419-37.

[78] Randelli P, Randelli F, Cabitza P, Vaienti L. The effects of COX-2 anti-inflammatory drugs on soft tissue healing: A review of the literature. J Biol Regul Homeost Agents 2010; 24(2): 107-14.

[79] Paoloni JA, Milne C, Orchard J, Hamilton B. Non-steroidal antiinflammatory drugs in sports medicine: Guidelines for practical but sensible use. Br J Sports Med 2009; 43(11): 863-5.

[80] Ferry ST, Dahners LE, Afshari HM, Weinhold PS. The effects of common anti-inflammatory drugs on the healing rat patellar tendon. Am J Sports Med 2007; 35(8): 1326-33.

[81] Paoloni JA, Orchard JW. The use of therapeutic medications for soft-tissue injuries in sports medicine. Med J Aust 2005; 183(7): 384-8.

[82] Fu RZ, Lin DD. Surgical and biomechanical perspectives on osteoarthritis and the ACL deficient knee: A critical review of the literature. Open Orthop J 2013; 7: 292-300.

[83] Buckwalter JA. Activity vs rest in the treatment of bone, soft tissue and joint injuries. Iowa Orthop J 1995; 15: 29-42.

[84] Panossian V, Liu SH, Lane JM, Finerman GA. Fibroblast growth factor and epidermal growth factor receptors in ligament healing. Clin Orthop Relat Res 1997; 342: 173-80. 
[85] Schmidt CC, Georgescu HI, Kwoh CK, et al. Effect of growth factors on the proliferation of fibroblasts from the medial collateral and anterior cruciate ligaments. J Orthop Res 1995; 13(2): 184-90.

[86] Boorman RS, Thornton GM, Shrive NG, Frank CB. Ligament grafts become more susceptible to creep within days after surgery: Evidence for early enzymatic degradation of a ligament graft in a rabbit model. Acta Orthop Scand 2002; 73: 568-74.

[87] Roy S, Loh H. Effects of Opioids on the immune system. Neurochem Res 1996; 21(11): 1375-86.

[88] Mehallo CJ, Drezner JA, Bytomski JR. Practical management: Nonsteroidal anti-inflammatory drug use in athletic injuries. Clin J Sports Med 2006; 16: 170-4.

[89] Dahners LE, Mullis BH. Effects of nonsteroidal anti-inflammatory drugs on bone formation and soft-tissue healing. J Am Acad Orthop Surg 2004; 12: 139-43.

[90] Radi ZA, Khan NK. Effects of cyclooxygenase inhibition on bone, tendon, and ligament healing. Inflamm Res 2005; 54: 358-66.

[91] Warden SJ, Avin KG, Beck EM, DeWolf ME, Hagemeir MA, Martin KM. Low-intensity pulsed ultrasound accelerates and a nonsteroidal anti-inflammatory drug delays knee ligament healing. Am J Sports Med 2006; 34: 1094-102

[92] Warden SJ. Cyclo-oxygenase-2 inhibitors: beneficial or detrimental for athletes with acute musculoskeletal injuries? Sports Med 2005; 35: 271-83.

[93] Ziltener JL, Leal S, Fournier PE. Non-steroidal anti-inflammatory drugs for athletes: An update. Ann Phys Med Rehab 2010; 53: 27882.

[94] Paoloni JA, Milne C, Orchard J, Hamilton B. Non-steroidal antiinflammatory drugs in sports medicine: Guidelines for practical but sensible use. Br J Sports Med 2009; 43: 863-5.

[95] Shapiro PS, Rohde RS, Froimson MI, Lash RH, Postak PA, Greenwald S. Corticosteroid or ketorolac exposure on histologic and biomechanical properties of rabbit tendon and cartilage. Hand 2007; 4: 165-72.

[96] Kapetanos G. The effect of the local corticosteroids on the healing and biomechanical properties of the partially injured tendon. Clin Orthop Relat Res 1982; 163: 170-9.

[97] Oxlund H. The influence of a local injection of cortisol on the mechanical properties of tendons and ligaments and the indirect effect on skin. Acta Orthop Scand 1980; 51:231-8.

[98] Scutt N, Rolf CG, Scutt A. Glucocorticoids inhibit tenocyte proliferation and tendon progenitor cell recruitment. J Orthop Res 2006; 24: 173-82.

[99] Fredberg U. Local corticosteroid injection in sport: Review of literature and guidelines for treatment. Scand J Med Sci Sports 1997; 7: 131-9.

[100] Distel LM, Best TM. Prolotherapy: A clinical review of its role in treating chronic musculoskeletal pain. PM R 2011; 3: S78-81.

[101] Goswami A. Prolotherapy. J Pain Palliat Care Pharmacother 2012; 26: 376-8.

[102] Lam S, van der Geest RN, Verhagen NA, et al. Connective tissue growth factor and IGF-1 are produced by human renal fibroblasts and cooperate in the induction of collagen production by high glucose. Diabetes 2003; 52: 2975-83.

[103] Clarkson MR, Murphy M, Gupta S, et al. High glucose-altered gene expression in mesangial cells. J Biol Chem 2002; 277: 970712.

[104] Woo SL, Hildebrand K, Watanabe N, Fenwick JA, Papageorgiou $\mathrm{CD}$, Wang JH. Tissue engineering of ligament and tendon healing. Clin Orthop Relat Res 1999; 367(Suppl): 312-4.

[105] Tang JB, Xu Y, Ding F, Wang XT. Tendon healing in vitro: promotion of collagen gene expression by bFGF with NF-kB gene activation. J Hand Surg 2003, 28: 215-20.

[106] Reeves KD, Fullerton BD, Topol G. Evidence-based regenerative injection therapy (Prolotherapy) in sports medicine. In: Seidenberg PH, Beutler PI, Eds. The Sports Medicine Resource Manual. Saunders (Elsevier) 2008; pp. 611-9.

[107] Vora A, Borg-Stein J, Nguyen RT. Regenerative injection therapy for osteoarthritis: Fundamental concepts and evidence-based review. PM R 2012; 4: S104-9.

[108] Hauser RA, Hauser MA, Baird NM. Evidence-based use of dextrose prolotherapy for musculoskeletal pain: A scientific literature review. J Prolotherapy 2011; 3(4): 765-89.
[109] Banks A. A rationale for prolotherapy. J Orthop Med 1991; 13: 549.

[110] Linetsky FS, Manchikanti L. Regenerative injection therapy for axial pain. Tech Reg Anesth Pain Manag 2005; 9: 40-9.

[111] DeChellis DM, Cortazzo MH. Regenerative medicine in the field of pain medicine: Prolotherapy, platelet-rich plasma therapy, and stem cell therapy. Tech Reg Anesth Pain Manag 2011; 15: 74-80.

[112] Fullerton BD. High-resolution ultrasound and magnetic resonance imaging to document tissue repair after prolotherapy: A report of 3 cases. Arch Phys Med Rehabil 2008; 89: 377-85.

[113] Maxwell NJ, Ryan MB, Taunton JE, Gillies JH, Wong AD. Sonographically guided intratendinous injection of hyperosmolar dextrose to treat chronic tendinosis of the Achilles tendon: A pilot study. AJR Am J Roentgenol 2007; 189: W215-20.

[114] Cusi M, Saunders J, Hungerford B, Wisbey-Roth T, Lucas P, Wilson S. The use of prolotherapy in the sacroiliac joint. Br J Sports Med 2010; 44: 100-4.

[115] Hooper RA, Frizzel JB, Faris P. Case series on chronic whiplash related neck pain treated with intraarticular zygapophysial joint regeneration injection therapy. Pain Physician 2007; 10: 313-8.

[116] Reeves KD, Hassanein KK. Randomized prospective double-blind placebo-controlled study of dextrose prolotherapy for knee osteoarthritis with or without ACL laxity. Alternative Ther 2000; 6: 68-79.

[117] Rabago D, Patterson JJ, Mundt M. Dextrose prolotherapy for knee osteoarthritis: A randomized controlled trial. Ann Fam Med 2013; 11: 229-37.

[118] Rabago D, Zgierska A, Fortney L, et al. Hypertonic dextrose injections (prolotherapy) for knee osteoarthritis: Results of a singlearm uncontrolled study with 1-year follow-up. J Altern Complement Med 2012; 18(4): 408-14.

[119] Reeves KD, Hassanein K. Long-term effects of dextrose prolotherapy for anterior cruciate ligament laxity. Altern Ther Health Med 2003; 9: 58-62.

[120] Rabago D, Lee KS, Ryan M. Hypertonic dextrose and morrhuate sodium injections (prolotherapy) for lateral epicondylosis (tennis elbow): Results of a single-blind, pilot level, randomized controlled trial. Am J Phys Med Rehabil 2013; 92: 587-96.

[121] Scarpone M, Rabago DP, Zgierska A. The efficacy of prolotherapy for lateral epicondylosis: A pilot study. Clin J Sport Med 2008; 18: 248-54.

[122] Yelland MJ, Sweeting KR, Lyftogt JA, Ng SK, Scuffham PA, Evans KA. Prolotherapy injections and eccentric loading exercises for painful Achilles tendinosis: A randomised trial. Br J Sports Med 2011; 45: 421-8.

[123] Topol GA, Reeves KD, Hassanein KM. Efficacy of dextrose prolotherapy in elite male kicking-sport athletes with groin pain. Arch Phys Med Rehabil 2005; 86: 697-702.

[124] Ryan MB, Wong AD, Gillies JH, Wong J, Taunton JE. Sonographically guided intratendinous injections of hyperosmolar dextrose/lidocaine: A pilot study for the treatment of chronic plantar fasciitis. Br J Sports Med 2009; 43: 303-6.

[125] Kim WM, Lee HG, Jeong CW, Kim CM, Yoon MH. A randomized controlled trial of intraarticular prolotherapy versus steroid injection for sacroiliac joint pain. J Altern Complement Med 2010; 16: $1285-90$.

[126] Lee JD, Lee DW, Jeong CW, Kim WM, Lee HG, Yoon MH. Effects of intraarticular prolotherapy on sacroiliac joint pain. Korean J Pain 2009; 22(3): 229-33.

[127] Khan SA, Kumar A, Varshney MK, Trikha V, Yadav CS. Dextrose prolotherapy for recalcitrant coccygodynia. J Orthop Surg 2008; 16(1): 27-9.

[128] Klein R, Patterson J, Eek B, Zeiger D. Prolotherapy for the treatment of back pain. American Association of Orthpaedic Medicine Position Statement 2006; pp. 1-5.

[129] Klein R, Eek B. Prolotherapy: An alternative way of managing low back pain. J Muscoskel Med 1997; 45-9.

[130] Centeno CJ, Elliott J, Elkins WL, Freeman M. Fluoroscopically guided cervical prolotherapy for instability with blinded pre and post radiographic reading. Pain Physician 2005; 8: 67-72.

[131] Hauser RA, Hauser MA, Holian P. Hackett-Hemwall dextrose prolotherapy for unresolved elbow pain. Pract Pain Manag 2009; 9(8): 14-26. 
[132] Kim JM. The effect of prolotherapy for osteoarthritis of the knee. J Korean Acad Rehab Med 2002; 26: 445-8.

[133] Ongly MJ, Dorman TA, Eek BC, Lundgren D, Klein RG. Ligament instability of knees: A new approach to treatment. Manual medicine 1988; 3: 152-4.

[134] Hauser RA, Hauser MA. Prolo Your Sports Injuries Away! Oak Park, IL: Beulah Land Press 2001.
[135] Hauser RA, Cukla JJ. Standard clinical x-ray studies document cartilage regeneration in five degenerated knees after prolotherapy. J Prolotherapy 2009; 1(1): 22-2.

[136] Hauser RA, Hauser MA. A retrospective study on HackettHemwall dextrose prolotherapy for chronic hip pain at an outpatient charity clinic in rural Illinois. J Prolotherapy 2009; 1(2): 76-88.

Received: June 03, 2014

Revised: June 18, 2014

Accepted: June 23, 2014

(C) Hauser et al.; Licensee Bentham Open.

This is an open access article licensed under the terms of the Creative Commons Attribution Non-Commercial License (http://creativecommons.org/licenses/by-nc/3.0/) which permits unrestricted, non-commercial use, distribution and reproduction in any medium, provided the work is properly cited. 